\title{
Synergistic Interaction Between Cationic Novel Gemini Surfactant and Non-ionic Conventional Surfactants in Aqueous Medium
}

\author{
Naved Azum ${ }^{1 *} \mathbb{D}$, Malik Abdul Rub ${ }^{1}{ }^{\mathbb{D}}$, Maha Moteb Alotaibi ${ }^{2}$, Anish Khan ${ }^{1}{ }^{\mathbb{D}}$, \\ Abdullah M. Asiri 1,2 (D) \\ 1 Center of Excellence for Advanced Materials Research, King Abdulaziz University, Jeddah 21589, Saudi Arabia; \\ navedazum@gmail.com (N.A.); malikrub@gmail.com (M.A.R.), anishkhan97@gmail.com (A.K.); \\ 2 Chemistry Department, Faculty of Science, King Abdulaziz University, Jeddah 21589, Saudi Arabia; \\ mmsalotaibi@kau.edu.sa (M.M.A.), aasiri2@kau.edu.sa (A.MA.); \\ * Correspondence: navedazum@gmail.com, nhassan2@kau.edu.sa (N.A.)
}

Scopus Author ID 56125590000

Received: 5.10.2021; Revised: 5.11.2021; Accepted: 8.11.2021; Published: 24.11.2021

\begin{abstract}
The interaction between novel gemini surfactant (alkane- $\alpha$, $\omega$-bis(dimethyl hexadecyl ammonium bromide) (G6)) and two different non-ionic surfactants (Triton X-114 (TX-114), Tween 20 (T-20)) has been investigated in the current study at temperature $298.15 \mathrm{~K}$. The critical micelle concentration $(\mathrm{cmc})$ values of mixed systems were computed by the conductometric titration in the aqueous medium. The results have been examined by utilizing numerous theoretical models (Clint, Rubingh, Motomura, Maeda, and Lange models). The experimentally determined cme were lower than corresponding ideal values ( $\left.\mathrm{cmc}^{*}\right)$ and decreased with the mixtures' stoichiometric mole fraction $\left(\alpha_{1}\right)$ of G6. This shows non-ideal behavior between two employed components. The interaction parameter at mixed micelle $(\beta)$ has been analyzed by using regular solution approximation. The attractive interaction or synergistic behavior in both mixed systems is confirmed by the negative values of $\beta$. The various energetics parameters were also evaluated and discussed.
\end{abstract}

Keywords: gemini surfactant; non-ionic surfactant; mixed micelle; synergistic interaction.

(C) 2021 by the authors. This article is an open-access article distributed under the terms and conditions of the Creative Commons Attribution (CC BY) license (https://creativecommons.org/licenses/by/4.0/).

\section{Introduction}

The molecules that can alter the properties of the surface or interface are known as surfactants or surface-active agents. They have dual characteristics: one affinity with water (polar material) and other affinities with non-polar materials. Surfactants in water demonstrate a high degree of cooperativity (self-aggregation) that results in the formation of micelle at the critical point (critical micelle concentration, cmc) [1-7]. Surfactants are the most significant demonstrative class of trade merchandise, have applications in most industries, i.e., domestic products, agricultural sprays, bio-catalysis, pharmaceuticals, and drug delivery [7-10]. Gemini or novel surfactants are a new class of surfactants having two amphiphilic moieties connected by a spacer group [11-17]. These novel surfactants have both institutional and industrial importance[18-25]. Gemini surfactants have better physicochemical properties than conventional surfactants, such as much greater efficiency in reducing the surface tension of water, lower cmc, unusual rheological properties, viscosity, etc.[26-28]. Gemini surfactants being easily cleavable molecules, show better stability and slow degradation. The quaternary 
ammonium gemini surfactants with a methylene chain are the most studied gemini surfactants used in phase catalysis because of high antibacterial activity [29]. Because of their higher cost, these novel surfactants are often used with conventional ionic, non-ionic, zwitterionic, and sugar-based surfactants because of their higher cost. Based on the above outstanding performance of gemini surfactants, it is important to study their behavior with other surfactants.

Typically, mixtures of different chemical species (one or two surfactants, dyes, electrolytes, and fillers) are used in the industries. Some of these are used to enhance interaction between them, while others control physical parameters ( $\mathrm{pH}$, ionic strength, viscosity, etc.) [30,31]. The mixture of one or more surfactants exhibits superior performance to those of single surfactants[32-36]. In mixtures, not only physicochemical properties of individual surfactants are enhanced, but also synergism is observed. For example, mixtures of a cationic surfactant with an anionic polyelectrolyte have been used to stabilize liquid foam stability [37]. Mixtures of surfactants are used in detergency, drug delivery, commercial industries, biological studies, medicine, etc. The colloidal and chemical properties of dispersed systems can easily be regulated with ionic and non-ionic surfactants. It is proved that the ionic-nonionic surfactants interaction at the surface and in bulk is superior to that between ionic-ionic, nonionic-nonionic mixed systems [38-40] as they minimize some unwanted interactions among ionic surfactants and the substrate. On the other hand, in germicide soaps, non-ionic surfactants are added with cationic surfactants $[41,42]$. Non-ionic surfactants have oxyethylene chains, so they are highly soluble in water [43]. They are widely used as solubilizing and emulsifying agents in textile, detergent, and cosmetic industries. These surfactants are used extensively in cleaning, cosmetics, and food products because they are biodegradable and safe for the skin. Nowadays, several molecular thermodynamics theories like Clint, Rubingh, Rosen, Motomura, Lange are available for forecasting the physicochemical properties in mixed systems. According to the molecular thermodynamic theory, the interaction between the ionic head group of ionic surfactants and the polar head group of non-ionic surfactants causes non-ideality. These types of interactions may be by electrostatic (among ionic hydrophilic groups), ion-dipole (among ionic and non-ionic hydrophilic groups), stearic (bulky groups), and van der Waals (among hydrophobic groups and hydrogen bonding) interaction. Generally, in forming the ionicnonionic mixed micelle, attractive interactions are involved that solubilize the colloids (size of ionic micelle increases), and thus the ability to solubilize different solutes increase. Due to the enormous industrial applications of ionic-nonionic surfactant mixtures, most of the studies on mixed micelles systems have been performed on a mixture of polyethylene and ionic surfactants [44-46].

The main aim of this study is to explore the composition of mixed micelle at the molecular level using different theoretical models, i.e., Clint, Rubingh, Motomura, Maeda, and Lange. The conductometric titration method was adopted in this study at $298.15 \mathrm{~K}$. The chosen surfactants in this study are widely used in different industrial areas. The selection of these surfactants is due to various hydrophobic chain lengths and large differences in the cmc values. The current study involves the determination and effects of non-ionic surfactants on the cmc of gemini surfactant. Various energetics parameters were also computed and discussed in the current work.

\section{Materials and Methods}

The non-ionic surfactants used in this study were Triton X-114 (TX-114) and polyoxyethylene (20) sorbitan monolaurate (tween-20). Tween-20 was purchased from Loba- 
Chemie (India), while TX-114 from Sigma (USA). The chemicals utilized for the synthesis of novel surfactants were 1,6-dibromohexane (Sigma-Aldrich, 0.97 (mass fraction)) and N, Ndimethyl hexadecyl amine (Sigma-Aldrich, 0.95 (mass fraction)). All chemicals were used as received, and no further purification was conducted. The double-distilled ultra-pure water having specific conductivity $(1-2) \times 10-6 \mathrm{ohm}^{-1} \mathrm{~cm}^{-1}$ was employed during the whole study.

\subsection{Synthesis of gemini surfactant.}

In 1974, Bunton et al.[16] first time studied the bis quaternary ammonium type surfactants (gemini). They designated the synthetic method and kinetics of these nucleophilic reactions. After a few years later, Devinsky et al. synthesized several bis quaternary ammonium surfactants and explored their micellization and surface activity of these surfactants [47]. The protocol of gemini synthesis is shown in Scheme 1.<smiles>CN(C)P[I-]Br</smiles>

$\mathrm{R}=\mathrm{CH}_{3}\left(\mathrm{CH}_{2}\right)_{15}$

Scheme 1. Protocol for the synthesis of gemini (G6) surfactant.

\subsection{Conductometric titration.}

The conductometric measurements were carried out using a conductivity meter (Equiptronic, EQ661, India) with a temperature compensation probe. The stock solutions of gemini and non-ionic surfactants were made in ultra-pure water and then desired mole fractions were obtained by mixing these solutions. The conductance was measured by adding a stock solution of a single cationic gemini surfactant or mixed with a non-ionic surfactant into the water using a microsyringe.

Table 1. Micellar parameters of G6+TX-114/T-20 mixtures at $T=298.15 \mathrm{~K}$.

\begin{tabular}{|c|c|c|c|c|c|c|c|c|}
\hline$\alpha_{1}$ & $\begin{array}{l}\text { cmc } \\
(\mathbf{m M})\end{array}$ & $\begin{array}{l}\text { cmc* } \\
(\mathbf{m M})\end{array}$ & $\mathbf{g}$ & $X_{1}^{\text {Rub }}$ & $X_{1}^{\text {ideal }}$ & $-\beta^{R u b}$ & $\mathbf{f}_{1}^{\text {Rub }}$ & $\mathbf{f}_{2}^{\text {Rub }}$ \\
\hline \multicolumn{9}{|c|}{ G6 + TX-114 } \\
\hline 0.0 & $0.263^{\mathrm{a}}$ & 0.263 & & & & & & \\
\hline 0.22 & 0.110 & 0.120 & 0.428 & 0.623 & 0.644 & 0.380 & 0.947 & 0.862 \\
\hline 0.33 & 0.090 & 0.094 & 0.210 & 0.738 & 0.759 & 0.271 & 0.981 & 0.863 \\
\hline 0.48 & 0.061 & 0.073 & 0.302 & 0.764 & 0.855 & 1.211 & 0.934 & 0.493 \\
\hline 0.57 & 0.047 & 0.064 & 0.358 & 0.748 & 0.895 & 2.129 & 0.873 & 0.303 \\
\hline 0.65 & 0.037 & 0.058 & 0.579 & 0.734 & 0.922 & 3.168 & 0.799 & 0.181 \\
\hline 1.0 & $0.041^{\mathrm{b}}$ & 0.041 & 0.460 & & & & & \\
\hline \multicolumn{9}{|c|}{ G6 + T-20 } \\
\hline 0.0 & $0.100^{c}$ & 0.100 & & & & & & \\
\hline 0.3 & 0.060 & 0.069 & 0.301 & 0.509 & 0.511 & 0.613 & 0.862 & 0.853 \\
\hline 0.4 & 0.056 & 0.063 & 0.274 & 0.597 & 0.619 & 0.513 & 0.920 & 0.832 \\
\hline 0.5 & 0.051 & 0.058 & 0.422 & 0.665 & 0.709 & 0.648 & 0.929 & 0.750 \\
\hline 0.6 & 0.048 & 0.054 & 0.399 & 0.731 & 0.785 & 0.652 & 0.953 & 0.705 \\
\hline 0.8 & 0.035 & 0.046 & 0.292 & 0.769 & 0.907 & 2.011 & 0.898 & 0.304 \\
\hline 1.0 & 0.041 & 0.041 & 0.460 & & & & & \\
\hline
\end{tabular}

Standard uncertainties $(\mathrm{u})$ are $\mathrm{u}(\mathrm{T})=0.1 \mathrm{~K}$. Relative standard uncertainties, $\mathrm{u}_{\mathrm{r}}(\mathrm{cmc} / \mathrm{cmc} *)= \pm 3 \%, \mathrm{u}_{\mathrm{r}}\left(\mathrm{X}_{1}^{\mathrm{Rub}} /\right.$ $\left.\mathrm{X}_{1}^{\text {ideal }}\right)= \pm 3 \%, \mathrm{u}_{\mathrm{r}}\left(\beta^{\text {Rub }}\right)= \pm 3 \%, \mathrm{u}_{\mathrm{r}}\left(\mathrm{f}_{1}^{\mathrm{Rub}} / \mathrm{f}_{2}^{\mathrm{Rub}}\right)= \pm 4 \%{ }^{\mathrm{a}}$ Ref. [49], ${ }^{\mathrm{b}}$ Ref. [48] and ${ }^{\mathrm{c}}$ Ref. [50]. 
All experiments were repeated at least three times. The cmc can be drawn from the intersection point of two linear segments (pre and post micellar regions) of the plot between specific conductivity vs. concentration (Figure 1). All data are listed in Table 1.

\section{Results and Discussion}

Figure 1 represents the variation of specific conductivity vs. concentration of gemini surfactant (G6) in the presence of non-ionic surfactant at $298.15 \mathrm{~K}$. The graph (Fig. 1) shows a typical character of gemini surfactant; first, specific conductivity increases linearly and after a critical point decreases. Below the critical point, the addition of surfactant to the water surges in the surfactant ions as well as counterions, subsequently, an upsurge in the specific conductivity of the solution.

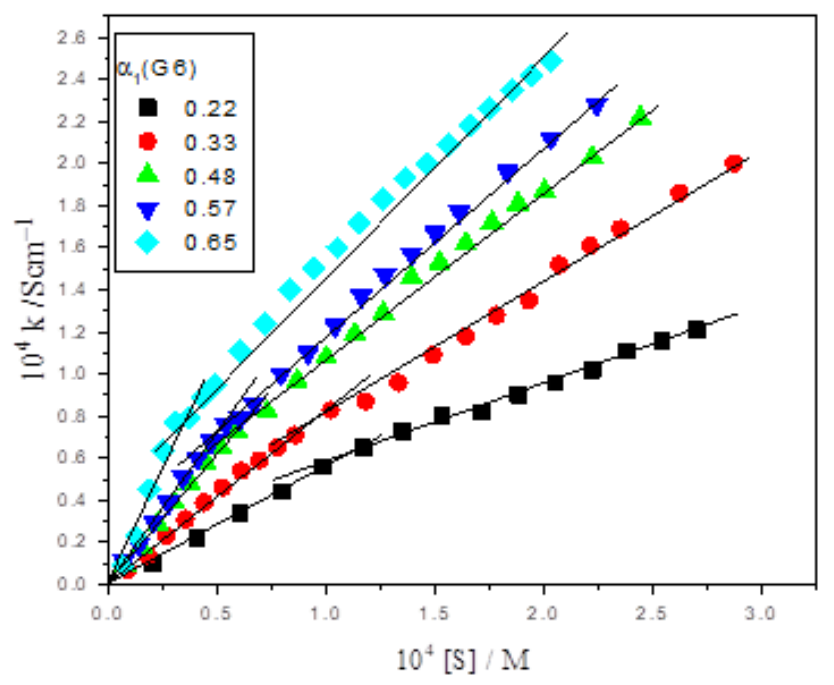

Figure 1. Plots of specific conductivity $(\kappa)$ vs. total surfactant concentration [S] for G6 + TX-114 mixed system at $298.15 \mathrm{~K}$.

On the other hand, above a critical point, more adding of surfactant increase the micelle concentration, although monomer concentration remains invariant. Since micelle is much larger than the monomer, it is transported more slowly through the solution and is a less efficient charge carrier. Thus, the rate of increase in the specific conductivity with surfactant concentration above the $\mathrm{cmc}$ is lower than below it. Thus, the intersection point provides a measure of the cmc. Therefore, the conductometric titration for the determination of $\mathrm{cmc}$ is found to be reliable and convenient. The cmc value for gemini surfactant is listed in Table 1 and is best matched with previous studies [48].

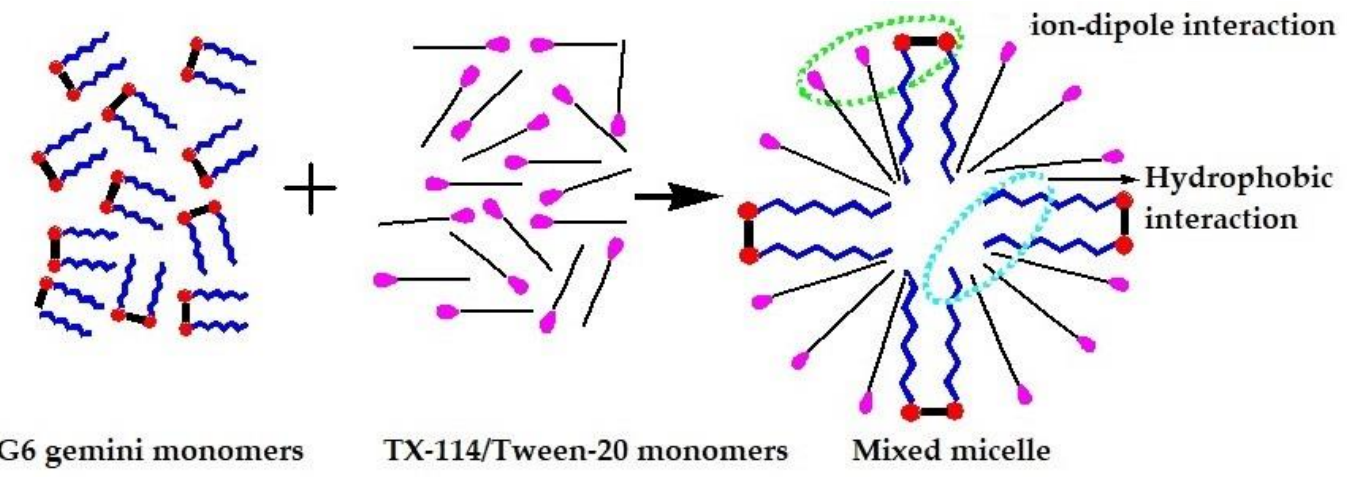

Scheme 2. Mixed micelle formation between gemini surfactant and non-ionic surfactant. 
The cmc values of non-ionic surfactants (TX-114 and Tween-20) could not determine by conductivity, so values are taken from earlier studies [49,50]. Among all surfactants, gemini surfactant has a lower cmc value because of two hydrocarbon chains present in the same molecule. Two factors depend on the micellization process (i) electrostatic interactions among the charged headgroups of the interacting components and (ii) hydrophobic interactions between interacting species due to their hydrocarbon tails. In the current investigations, cationic and non-ionic surfactants try to interact with each other by dipole and positive charge G6 head group electrostatically (scheme 2).

An ionic surfactant having positive or negative charged head groups often bind a considerable fraction of counterions that can be conveniently quantified from electrochemical measurements. The counterions are bound strongly with the Stern layer (the layer just adjacent to the surface of the micelle) and drift with micelle when an electric field is applied. A sharp break in specific conductivity vs. concentration isotherm results from surface charge neutriliztion[51-55]. At low concentrations, amphiphiles behave like strong electrolytes and dissociate completely, and their conductance increases linearly up to cmc. After cmc the rate decreases due to the binding of some counterions to the micelle. The fraction of counterions bound to the micelle was determined by conductometric titration. In the earlier studies, the following procedure is obeyed to determine the counterion binding $(\mathrm{g})[56]$ :

$$
\mathrm{g}=1-\frac{S_{2}}{S_{1}}
$$

where $S_{2}$ and $S_{1}$ are the slopes of specific conductivity vs. concentration profile. The values of $\mathrm{g}$ are listed in Table 1. With the addition of non-ionic surfactants in the gemini surfactant solution, $g$ values decrease at almost all mole fractions. The lower counterion binding ( $\mathrm{g}$ ) of the mixture is due to the reduced charge density of the mixture. The lower counterion binding increases the cmc values.

\subsection{Interaction of G6 with TX-114 \& T-20.}

\subsubsection{Clint model.}

The ideality or non-ideality of a mixed surfactant system can be judged by the Clint model by using cmc for pure surfactants and stoichiometric composition values [57]. If it is assumed that the mixed micelle formed by the two or more amphiphiles behave ideally, the Clint equation for mixed binary system can be written as

$$
\frac{1}{c m c^{*}}=\frac{\alpha_{1}}{c m c_{1}}+\frac{\alpha_{2}}{c m c_{2}}
$$

where $\alpha_{1}$ and $\alpha_{2}$ are the mole fractions of components 1 and 2. The above equation was suggested by Clint [57] for the ideal mixed systems, and the cmc values calculated by the Clint equation are reflected as ideal $\mathrm{cmc}$ values $\left(\mathrm{cmc}^{*}\right)$. The experimental $\mathrm{cmc}$ and ideal $\mathrm{cmc}$ values concerning the mole fraction are plotted in Figure 2. 


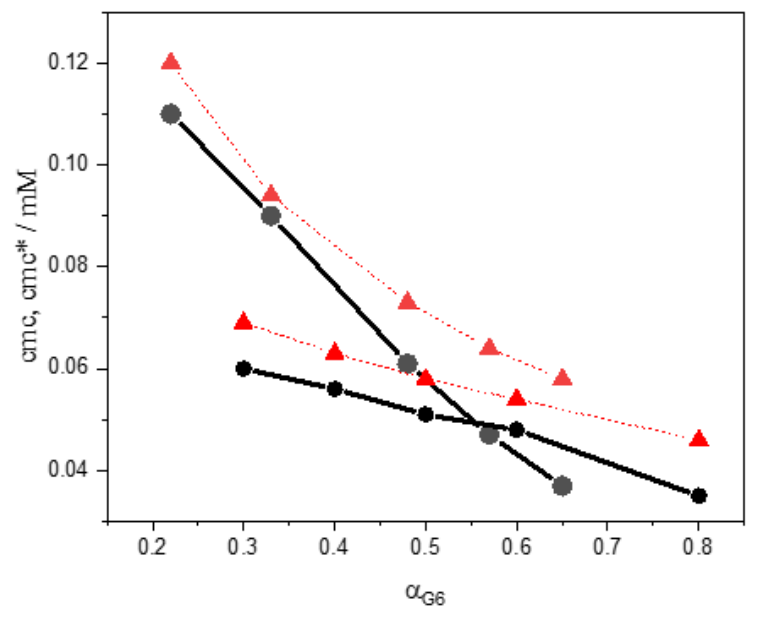

Figure 2. Experimental critical micelle concentration, $\mathrm{cmc}(\mathcal{O})$ and ideal critical micelle concentration, $\mathrm{cmc}^{*}$ (A) as a mole fraction of gemini, G6 for G6 + TX-114/T-20 mixed systems. Solid lines represent experimental data, and dash lines represent ideal values.

The ideal $\mathrm{cmc}$ values are more than experimental $\mathrm{cmc}$ values, as clear from Table 1 data and Figure 2. The negative deviation from equation 2 (lower experimental $\mathrm{cmc}$ value than ideal) for mixture specifies synergistic and non-ideal behavior between the two surfactants mixtures. However, positive deviation from equation (2) implies antagonistic (repulsive interactions) behavior of mixed systems.

\subsubsection{Rubingh model.}

The strong negative deviation of ideal $\mathrm{cmc}\left(\mathrm{cmc}^{*}\right)$ from experimental $\mathrm{cmc}$ was also observed by Rubingh [58]. The Rubingh model is based on regular solution approximation (RST), giving the relation between two cmcs as follows:

$$
\frac{1}{c m c^{*}}=\sum_{i=1}^{n} \frac{\alpha_{i}}{f_{i}^{R u b} c m c_{i}}
$$

Where $f_{i}^{R u b}$ is the activity coefficient of the ith component in the mixed micelle calculated by equations $4 \& 5$ for the two components system:

$$
\begin{gathered}
f_{1}^{R u b}=\exp \left[\beta\left(1-X_{1}^{R u b}\right)^{2}\right] \\
f_{2}^{R u b}=\exp \left[\beta\left(X_{1}^{R u b}\right)^{2}\right]
\end{gathered}
$$

Table 1 shows the values of $f_{1}^{R u b}$ and $f_{2}^{R u b}$. The values of the activity coefficient $f_{i}^{R u b}=1$ indicates an ideal mixed system. However, a value less than 1 indicates the non-ideal behavior of mixed components. For current mixed systems, the values of activity coefficients were very low, lower than unity confirms synergistic interaction amid G6 and TX-114/T-20, and the mixed micelles are formed at lower concentrations with high propensity. In the above equations ( $4 \& 5$ ), the term $\beta$ is a parameter to indicate whether there is attractive or repulsive behavior between mixed components. The positive, negative, and zero values of $\beta$ represent antagonism, synergism, and no interaction between two components in the mixed micelle. The $\beta$ can be estimated by the equation (6).

$$
\beta=\frac{\ln \left(\alpha_{1} c m c / X_{1}^{R u b} c m c_{1}\right)}{\left(1-X_{1}^{R u b}\right)^{2}}
$$

Here $X_{1}^{R u b}$ is the micellar mole fraction of composition of component 1 (G6). Table 1 reveals the values of $\beta$. The negative values of $\beta$ presented in Table 1 indicate the synergistic 
or attractive interaction between two surfactants molecules. The attractive interaction between two surfactants depends not only on attraction but also on the relevant properties of individual surfactants in the mixture. The non-ionic surfactants have a huge number of oxygens with unpaired electrons and tend to interact with cationic gemini surfactant coulombically. The $\beta$ values of the G6/T-20 system are less than G6/TX-114. This phenomenon can be explained based on the structure of T-20. The T-20 molecules have a very compact structure that creates crowding in the micellar core that causes steric hindrance and, hence, weaker interaction.

The composition of mixed components in mixed micelles is an important parameter; by adjusting its value, the desirable properties for a specific application can be obtained. To calculate its value (composition of mixed micelle) is tough and a major problem since the value is fixed by the partition equilibria of the species between aggregates and the surrounding medium. It is quite difficult to estimate composition directly by experimental analysis, so it is estimated using theoretical models parameterized with physicochemical properties. The value of $X_{1}^{R u b}$ (composition of G6 in mixed micelles) can be computed by equation (7) iteratively [44].

$$
\frac{\left(X_{1}^{R u b}\right)^{2} \ln \left(\alpha_{1} c m c / X_{1}^{R u b} c m c_{1}\right)}{\left(1-X_{1}^{R u b}\right)^{2} \ln \left[\left(1-\alpha_{1}\right) c m c /\left(1-X_{1}^{R u b}\right) c m c_{2}\right]}=1
$$

The value $X_{1}^{R u b}$ are given in Table 1, and it is concluded that the composition of G6 in mixed micelles was attained than TX-114/T-20. The data (Table 1) show strong, attractive interaction for both mixed systems and greater in the case of G6+TX-114 mixed systems.

The ideal values of the micellar mole fraction can be computed by the Motomura theory [59].

$$
X_{1}^{\text {ideal }}=\frac{\alpha_{1} c m c_{2}}{\alpha_{1} c m c_{2}+\alpha_{2} c m c_{1}}
$$

There is a deviation in the values of $X_{1}^{\text {ideal }}$ from $X_{1}^{R u b}$ (Table 1), this shows the presence of synergism between current mixed systems. On increasing the concentration of G6 a large number of G6 molecules take part in the formation of the mixed micelle, so, the $X_{1}^{R u b}$ values increase with the increase in the stoichiometric mole fraction $\left(\alpha_{1}\right)$ of G6. The $X_{1}^{\text {ideal }}$ values are greater than the $X_{1}^{R u b}$ values confirm the G6 molecules contribute less towards mixed micelles than in its ideal mixing state, and a larger number of non-ionic surfactants molecules transfer from solution to micellar phase.

\subsubsection{Maeda model.}

The evaluated interaction parameter $\beta$ is beneficial to understand the interaction between two surfactants. In the Rubingh theory [44], only head group-head group interaction is considered. However, according to Maeda [60], when the chains are unlike in length, both head group-head group and chain-chain interactions should also be stated for the mixed micelle. For an ionic-nonionic mixed system, the $\mathrm{cmc}$ of the mixture should be much lower than single surfactants. This is possible when the non-ionic surfactant molecules between the head group of cationic surfactants lower the head group repulsion (Scheme 2). Maeda suggests a parameter $B_{1}$ that determines chain-chain interaction and contributes to the stability of mixed micelle. The free energy of micellization $\left(\Delta G_{M}\right)$ according to Maeda can be calculated by the following equation [60]

$$
\Delta G_{M}=R T\left(B_{0}+B_{1} X_{1}^{R u b}+B_{2}\left(X_{1}^{R u b}\right)^{2}\right)
$$

where 


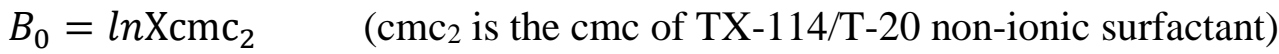

$B_{1}+B_{2}=\ln \frac{\mathrm{Xcmc}_{1}}{\mathrm{Xcmc}_{2}} \quad\left(\mathrm{cmc}_{1}\right.$ is the cmc of G6 ionic surfactant $)$

$B_{2}=-\beta$

The values of all the above parameters are listed in Table 2 .

Table 2. Micellar parameters of G6+TX-114/T-20 mixtures at $\mathrm{T}=298.15 \mathrm{~K}$.

\begin{tabular}{|c|c|c|c|c|c|c|}
\hline$\alpha_{1}$ & $\boldsymbol{B}_{2}$ & $-B_{1}$ & $-B_{0}$ & $\mathbf{X}_{1}^{\text {Rod }}$ & $\mathbf{f}_{1}^{\text {Rod }}$ & $\mathbf{f}_{2}^{\text {Rod }}$ \\
\hline \multicolumn{7}{|c|}{ G6 + TX-114 } \\
\hline 0.22 & 0.38 & 2.238 & \multirow[t]{5}{*}{12.25} & 0.659 & 0.947 & 0.865 \\
\hline 0.33 & 0.27 & 2.128 & & 0.895 & 0.981 & 0.875 \\
\hline 0.48 & 1.21 & 3.068 & & - & - & - \\
\hline 0.57 & 2.12 & 3.978 & & - & - & - \\
\hline 0.65 & 3.16 & 5.018 & & - & - & - \\
\hline \multicolumn{7}{|c|}{ G6 + T-20 } \\
\hline 0.3 & 0.61 & 1.501 & \multirow[t]{5}{*}{13.23} & 0.520 & 0.862 & 0.855 \\
\hline 0.4 & 0.51 & 1.402 & & 0.652 & 0.920 & 0.838 \\
\hline 0.5 & 0.65 & 1.541 & & 0.762 & 0.929 & 0.756 \\
\hline 0.6 & 0.65 & 1.542 & & 0.852 & 0.954 & 0.708 \\
\hline 0.8 & 2.01 & 2.902 & & 0.968 & 0.898 & 0.306 \\
\hline
\end{tabular}

Standard uncertainties $(\mathrm{u})$ are $\mathrm{u}(\mathrm{T})=0.1 \mathrm{~K}$. Relative standard uncertainties, $\mathrm{u}_{\mathrm{r}}\left(\mathrm{X}_{1}^{\text {Rod }}\right)= \pm 3 \%, \mathrm{u}_{\mathrm{r}}\left(\mathrm{f}_{1}^{\text {Rod }} / \mathrm{f}_{2}^{\text {Rod }}\right)=$ $\pm 4 \%$.

The parameter $B_{1}$ is subordinated with standard free energy change when an ionic surfactant substitutes a non-ionic surfactant. It is clear from the Table 2 data that on increasing the mole fraction of G6, the values of $B_{1}$ are also increased with few exceptions, confirming that the chain-chain interaction also enhances with mole fraction. Table 3 depicted that the $\Delta G_{\mathrm{M}}$ (Maeda) value thoroughly was obtained negative along with their magnitude increases through an increase in $\alpha_{1}$ value of G6, viewing that formed micelles are stable and their stability further increases with rising of $\alpha_{1}$ value. Table 3 also revealed that the values of $\Delta \mathrm{G}_{\mathrm{m}}$ and $\Delta G_{\mathrm{M}}$ diverged largely with each other.

\subsubsection{Rodenas model.}

The mixed micelle data were also analyzed by using the Rodenas model [61] based on Lange's model [62]. Rodenas relates the chemical potential of components in mixed micelle by using Gibbs-Duhem, a thermodynamic equation. According to this model, the micellar mole fractions of component 1 can be computed by the following equation:

$$
X_{1}^{R o d}=-\left(1-y_{1}\right) y_{1} \frac{d l n c m c}{d y_{1}}+y_{1}
$$

The obtained values of $X_{1}^{R o d}$ are tabulated in Table 2. The $X_{1}^{R u b}$ and $X_{1}^{\text {Rod }}$ values for both mixed systems are higher than the stoichiometric mole fractions of G6. Like $X_{1}^{R u b}$, the $X_{1}^{R o d}$ values also increase with the increasing $\alpha_{1}$ seeing that the composition of G6 increases in mixed micelles with mole fraction (Table 2). The activity coefficients values are also estimated by using the subsequent equations

$$
\begin{gathered}
f_{1}^{\text {Rod }}=\frac{\alpha_{1} c m c}{X_{1}^{\text {Rod }} c m c_{1}} \\
f_{2}^{\text {Rod }}=\frac{\alpha_{2} c m c}{X_{2}^{\text {Rod } c m c_{2}}}
\end{gathered}
$$

The estimated values of $f_{1}^{\text {Rod }}$ and $f_{2}^{\text {Rod }}$ were tabulated in Table 2 . The values of both parameters were less than 1, indicating the non-ideal behavior of mixed systems. 


\subsubsection{Thermodynamics of micellization.}

To get more information related to interactions from current data, the thermodynamic parameters have been computed and examined. The non-ideal free energy of micelle formation can be computed with the support of equation (14)[63-65].

$$
\Delta G_{m}=R T\left[X_{1}^{R u b} \ln \left(X_{1}^{R u b} f_{1}^{R u b}\right)+X_{2}^{R u b} \ln \left(X_{2}^{R u b} f_{2}^{R u b}\right)\right]
$$

On the other hand, for ideal mixed systems, the values of $f_{1}$ and $f_{2}$ are equivalent to 1 , the free energy of micellization for ideal mixing can be estimated by the following equation[63,66].

$$
\Delta G_{m}^{\text {ideal }}=R T\left[X_{1}^{R u b} \ln X_{1}^{R u b}+X_{2}^{R u b} \ln X_{2}^{R u b}\right]
$$

The values $\Delta G_{m}$ and $\Delta G_{m}^{i d e a l}$ are listed in Table 3 are always negative, which designated that the creation of mixed micelle is spontaneous and thermodynamically stable. By utilizing regular solution approximation, different thermodynamic parameters can be estimated by considering that the excess entropy of mixing is zero [67]. The energetic parameters like excess enthalpy, enthalpy of micellization, and Gibbs excess free energy, can be estimated by the equation [63-66].

$$
G^{e x}=H^{e x}=\Delta H_{m}=R T\left[X_{1}^{R u b} \ln f_{1}^{R u b}+X_{2}^{R u b} \ln f_{2}^{R u b}\right]
$$

Two factors contribute to change in enthalpy of micellization $\left(\Delta H_{m}\right)$, (i) the loss of translation energy due to hydrophobic and electrostatic interaction in the micellization, the energy released (ii) to break the organized structure of water, the energy is required. As clear from Table 3 that on increasing the mole fraction of G6, hydrophobic interaction increases, leading to a more exothermic process of micellization (only for G6 + TX-114). For G6 + T-20

\begin{tabular}{|c|c|c|c|c|c|c|c|}
\hline$\alpha_{1}$ & $\begin{array}{l}-\Delta \mathbf{G}_{\mathbf{m}} \\
\left(\mathbf{k j} \cdot \mathbf{m o l}^{-1}\right)\end{array}$ & $\begin{array}{l}-\Delta \mathbf{G}_{\mathbf{m}}^{\text {ideal }} \\
\left(\mathbf{k j} \cdot \mathbf{m o l}^{-1}\right)\end{array}$ & $\begin{array}{c}-\mathbf{G}_{\mathrm{exc}}^{\mathrm{Rub}}=\Delta \mathbf{H}_{\mathrm{m}} \\
\left(\mathbf{k j} \cdot \mathbf{m o l}^{-1}\right)\end{array}$ & $\begin{array}{c}-\mathrm{G}_{\text {exc }}^{\mathrm{Rod}} \\
\left(\mathbf{k j} \cdot \mathbf{m o l}^{-1}\right)\end{array}$ & $\begin{array}{c}\Delta S_{\mathbf{m}} \\
\left(J^{-1} \mathbf{m o l}^{-1}\right)\end{array}$ & $\begin{array}{l}-\Delta G_{\mathrm{M}} \\
\left(\mathbf{k j} \cdot \mathrm{mol}^{-1}\right)\end{array}$ & $\begin{array}{l}\mid \mathbf{T} \Delta \mathbf{S}_{\mathbf{m}} \\
\left|\Delta \mathbf{G}_{\mathbf{m}}\right|\end{array}$ \\
\hline \multicolumn{8}{|c|}{ G6 + TX-114 } \\
\hline 0.22 & 1.599 & 1.641 & 0.221 & 0.210 & 4.627 & 33.440 & 0.86 \\
\hline 0.33 & 1.339 & 1.424 & 0.129 & 0.076 & 4.059 & 33.879 & 0.90 \\
\hline 0.48 & 1.053 & 1.353 & 0.541 & - & 1.719 & 34.409 & 0.45 \\
\hline 0.57 & 1.050 & 1.398 & 0.994 & - & 0.187 & 34.784 & 0.05 \\
\hline 0.65 & 1.128 & 1.435 & 1.532 & - & - & 35.258 & - \\
\hline \multicolumn{8}{|c|}{ G6 + T-20 } \\
\hline 0.3 & 2.418 & 1.716 & 0.379 & 0.376 & 6.839 & 34.280 & 0.84 \\
\hline 0.4 & 2.406 & 1.670 & 0.306 & 0.287 & 7.048 & 34.401 & 0.87 \\
\hline 0.5 & 2.228 & 1.579 & 0.358 & 0.302 & 6.277 & 34.606 & 0.84 \\
\hline 0.6 & 1.803 & 1.442 & 0.317 & 0.226 & 4.986 & 34.709 & 0.82 \\
\hline 0.8 & 2.144 & 1.339 & 0.885 & 0.352 & 4.226 & 35.361 & 0.59 \\
\hline
\end{tabular}
no specific trend is obtained.

Table 3. Thermodynamic parameters of G6+TX-114/T-20 mixtures at $\mathrm{T}=298.15 \mathrm{~K}$.

The entropy change for micellization can be estimated from the equation:

$$
\Delta S_{m} \frac{\Delta H_{m}-\Delta G_{m}}{T}
$$

The values of all the above thermodynamic parameters are listed in Table 3 . For current investigated mixed systems, the positive entropy values can be considered the driving force of micelle formation. It is also concluded from the entropy data that in the G6 + T-20 mixed system, the entropic contribution was a little larger than G6 + TX-114. The G6 + TX-114 mixed system was a well-organized mixed micelle, so it has fewer entropy values. 


\section{Conclusions}

The surfactants are utilized in a wide spectrum of industries. Almost in all applications, surfactants are used with different kinds of additives to obtain better action of the mixture over a single one. The combination of two or more surfactants exhibits pronounced synergistic effects by reducing the cmc values of the mixture. Keeping the view of the superiority of gemini surfactants on the micellar front, the mixed surfactants behavior of gemini surfactants with two non-ionic surfactants has been explored in the current study. Following conclusions have been drawn from this study: The non-ideal behavior of current mixed systems has been confirmed by the lower experimental $\mathrm{cmc}$ values than the ideal one; The cmc values decrease with the mole fractions of novel surfactants; The strong synergistic or attractive interaction was confirmed by the negative values of the interaction parameter at all mole fractions; The values $\Delta G_{m}$ and $G^{e x}$ are negative, which designated that the creation of mixed micelle is spontaneous and thermodynamically stable. The stability of the current mixed system is also supported by the interaction parameter; The exothermic nature of the current mixed system is governed by the negative values of enthalpy change $\left(\Delta H_{m}\right)$. The positive entropy values can be considered as the driving force of micelle formation.

\section{Funding}

This research work was funded by Institutional Fund Projects under grant no (IFPRC-174-1302020). Therefore, the authors gratefully acknowledge technical and financial support from the Ministry of Education and King Abdulaziz University, Jeddah, Saudi Arabia.

\section{Acknowledgments}

This research work was funded by Institutional Fund Project under grant no (IFPRC-174-1302020). Therefore, the authors gratefully acknowledge technical and financial support from the Ministry of Education and King Abdulaziz University, Jeddah, Saudi Arabia.

\section{Conflicts of Interest}

The authors declare no conflict of interest.

\section{References}

1. Menger, F.M.; Littau, C.A. Gemini-surfactants: synthesis and properties. J. Am. Chem. Soc. 1991, 113, 14511452, https://doi.org/10.1021/ja00004a077.

2. Kumar, A.; Kaur, G.; Kansal, S.K.; Chaudhary, G.R.; Mehta, S.K. (Cationic + non-ionic) mixed surfactant aggregates for solubilisation of curcumin. J. Chem. Thermodyn. 2016, 93, 115-122, https://doi.org/10.1016/j.jct.2015.09.027.

3. Azum, N.; Rub, M.A.; Asiri, A.M. Micellization and interfacial behavior of binary and ternary mixtures in aqueous medium. J. Mol. Liq. 2016, 216, 94-98, https://doi.org/10.1016/j.molliq.2016.01.001.

4. Azum, N.; Rub, M.A.; Asiri, A.M.; Kashmery, H.A. Synergistic effect of an antipsychotic drug chlorpromazine hydrochloride with pluronic triblock copolymer: A physicochemical study. J. Mol. Liq. 2018, 260, 159-165, https://doi.org/10.1016/j.molliq.2018.03.088.

5. Fainerman, V.B., Mobius, D., Miller, R. Surfactants: Chemistry, Interfacial Properties, Applications. Elsevier Science, 2001.

6. Porter, M.R. Handbook of Surfactants; Springer Science: New York, 1993.

7. Romsted, L.S., Ed. Surfactant Science and Technology: Retrospects and Prospects; CRC Press: Boca Raton, London, New York. 
8. Holmberg, K. Novel Surfactants, Preparation Application and Biodegradability 2003.

9. Singh, A.; Van Hamme, J.D.; Ward, O.P. Surfactants in microbiology and biotechnology: Part 2. Application aspects. Biotechnol. Adv. 2007, 25, 99-121, https://doi.org/10.1016/j.biotechadv.2006.10.004.

10. Gull, N.; Sen, P.; Khan, R.H.; Kabir-ud-Din Interaction of Bovine (BSA), Rabbit (RSA), and Porcine (PSA) Serum Albumins with Cationic Single-Chain/Gemini Surfactants: A Comparative Study. Langmuir 2009, 25, 11686-11691, https://doi.org/10.1021/la901639h.

11. Azum, N.; Rub, M.A.; Asiri, A.M. Interaction of triblock-copolymer with cationic gemini and conventional surfactants: A physicochemical study. J. Dispers. Sci. Technol. 2017, 38, 1785-1791, https://doi.org/10.1080/01932691.2017.1283510.

12. Kumar, D.; Rub, M.A.; Azum, N.; Asiri, A.M. Mixed micellization study of ibuprofen (sodium salt) and cationic surfactant (conventional as well as gemini). J. Phys. Org. Chem. 2018, 31, e3730, https://doi.org/10.1002/poc.3730.

13. Kumar, D.; Azum, N.; Rub, M.A.; Asiri, A.M. Aggregation behavior of sodium salt of ibuprofen with conventional and gemini surfactant. J. Mol. Liq. 2018, 262, 86-96, https://doi.org/10.1016/j.molliq.2018.04.053.

14. Azum, N.; Rub, M.A.; Asiri, A.M. Interaction of antipsychotic drug with novel surfactants: Micellization and binding studies. Chin. J. Chem. Eng. 2018, 26, 566-573, https://doi.org/10.1016/j.cjche.2017.09.009.

15. Wu, Z.-Y.; Fang, Z.; Qiu, L.-G.; Wu, Y.; Li, Z.-Q.; Xu, T.; Wang, W.; Jiang, X. Synergistic inhibition between the gemini surfactant and bromide ion for steel corrosion in sulphuric acid. J. Appl. Electrochem. 2009, 39, 779-784, https://doi.org/10.1007/s10800-008-9720-2.

16. Bunton, C.A.; Robinson, L.B.; Schaak, J.; Stam, M.F. Catalysis of nucleophilic substitutions by micelles of dicationic detergents. J. Org. Chem. 1971, 36, 2346-2350, https://doi.org/10.1021/jo00815a033.

17. Menger, F.M.; Keiper, J.S. Gemini Surfactants. Angew. Chemie Int. Ed. 2000, 39, 1906-1920, https://doi.org/10.1002/1521-3773(20000602)39:11<1906::AIDANIE1906>3.0.CO;2-Q.

18. Wen, Y.; Ge, X.; Gao, W.; Wei, W.; Qiao, Y.; Chang, H. Synthesis and aggregation properties of ethylene glycol ester-based cationic Gemini surfactants. Colloid Interface Sci. Commun. 2020, 37, 100274, https://doi.org/10.1016/j.colcom.2020.100274.

19. Shaban, S.M.; Elsamad, S.A.; Tawfik, S.M.; Abdel-Rahman, A.A.-H.; Aiad, I. Studying surface and thermodynamic behavior of a new multi-hydroxyl Gemini cationic surfactant and investigating their performance as corrosion inhibitor and biocide. J. Mol. Liq. 2020, 316, 113881, https://doi.org/10.1016/j.molliq.2020.113881.

20. Tariq, Z.; Kamal, M.S.; Mahmoud, M.; Shakil Hussain, S.M.; Hussaini, S.R. Novel gemini surfactant as a clay stabilizing additive in fracturing fluids for unconventional tight sandstones: Mechanism and performance. J. Pet. Sci. Eng. 2020, 195, 107917, https://doi.org/10.1016/j.petrol.2020.107917.

21. Gu, Y.; Zhou, M.; Wang, X.; Tu, H.; Yang, Y.; Zhao, Y. Preparation and performance evaluation of sulfatequaternary ammonium Gemini Surfactant. J. Mol. Liq. 2021, 117665, https://doi.org/10.1016/j.molliq.2021.117665.

22. Xiao, T.; Luo, W.; Wei, J.; Yuan, X.; Huang, Q.; Zou, L.; Zhang, M.; Antwi, P.; Zhang, D.; Ren, S. Adsorption of tungstate using cationic gemini surfactant-modified montmorillonite: Influence of alkyl chain length. Colloids Surfaces A Physicochem. Eng. Asp. 2021, 629, 127484, https://doi.org/10.1016/j.colsurfa.2021.127484.

23. Pal, N.; Hoteit, H.; Mandal, A. Structural aspects, mechanisms and emerging prospects of Gemini surfactantbased alternative Enhanced Oil Recovery technology: A review. J. Mol. Liq. 2021, 339, 116811, https://doi.org/10.1016/j.molliq.2021.116811.

24. Bhattarai, A.; Saha, B.; Jaffari, Z.H.; Rub, M.A.; Alghamdi, Y.G.; Kumar, D. Analysis of interaction between glutamic acid and ninhydrin in the presence of acetate buffer solvent: Impact of gemini (twin-headed) surfactants. Colloids Surfaces A Physicochem. Eng. Asp. 2021, 626, 127061, https://doi.org/10.1016/j.colsurfa.2021.127061.

25. Brycki, B.; Szulc, A. Gemini surfactants as corrosion inhibitors. A review. J. Mol. Liq. 2021, 117686, https://doi.org/10.1016/j.molliq.2021.117686.

26. Lundberg, D.; Stjerndahl, M.; Holmberg, K. Mixed Micellar Systems of Cleavable Surfactants. Langmuir 2005, 21, 8658-8663, https://doi.org/10.1021/la051162h.

27. Král'ová, K.; Šeršeň, F.; Devínsky, F.; Lacko, I. Photosynthesis-inhibiting Effects of Cationic Biodegradable Gemini Surfactants. Tenside Surfactants Deterg. 2010, 47, 288-293, https://doi.org/10.3139/113.110079.

28. Kuo, C.-F.J.; Lin, L.-H.; Dong, M.-Y.; Chang, W.-S.; Chen, K.-M. Preparation and Properties of New Ester- 
Linked Cleavable Gemini Surfactants. J. Surfactants Deterg. 2011, 14, 195-201, https://doi.org/10.1007/s11743-010-1232-5.

29. Imam, T.; Devinsky, F.; Lacko, I.; Mlynarcik, D.; Krasnec, L. ChemInform bisquaternary ammonium salt. part 3. preparation and antimicrobial activity of some new bisquaternary ammonium salts. Chem. Informationsd. 1983, 14, https://doi.org/10.1002/chin.198340149.

30. Khan, A.; Marques, E.F. Synergism and polymorphism in mixed surfactant systems. Curr. Opin. Colloid Interface Sci. 1999, 4, 402-410, https://doi.org/10.1016/S1359-0294(00)00017-0.

31. Hines, J.D.; Garrett, P.R.; Rennie, G.K.; Thomas, R.K.; Penfold, J. Structure of an Adsorbed Layer of n Dodecyl- N , N -dimethylamino Acetate at the Air/Solution Interface As Determined by Neutron Reflection. J. Phys. Chem. B 1997, 101, 7121-7126, https://doi.org/10.1021/jp9711959.

32. Kumar, D.; Azum, N.; Rub, M.A.; Asiri, A.M. Interfacial and spectroscopic behavior of phenothiazine drug/bile salt mixture in urea solution. Chem. Pap. 2021, 75, 3949-3956, https://doi.org/10.1007/s11696021-01634-7.

33. Rub, M.A.; Azum, N.; Khan, F.; Asiri, A.M. Aggregation of sodium salt of ibuprofen and sodium taurocholate mixture in different media: A tensiometry and fluorometry study. J. Chem. Therm. 2018, 121, 199-210, https://doi.org/10.1016/j.jct.2018.02.019.

34. Azum, N.; Rub, M.A.; Asiri, A.M. Bile salt-bile salt interaction in mixed monolayer and mixed micelle formation. J. Chem. Therm. 2019, 128, 406-414, https://doi.org/10.1016/j.jct.2018.08.030.

35. Naqvi, A.Z.; Kabir-ud-Din; Panda, M. Mixed micellization: Improved physicochemical behavior of different amphiphiles in presence of gemini surfactants. J. Mol. Liq. 2021, 343, 116876, https://doi.org/10.1016/j.molliq.2021.116876.

36. Azum, N.; Ahmed, A.; Rub, M.A.; Asiri, A.M.; Alamery, S.F. Investigation of aggregation behavior of ibuprofen sodium drug under the influence of gelatin protein and salt. J. Mol. Liq 2019, 290, 111187, https://doi.org/10.1016/j.molliq.2019.111187.

37. Lencina, M.M.S.; Fernández Miconi, E.; Fernández Leyes, M.D.; Domínguez, C.; Cuenca, E.; Ritacco, H.A. Effect of surfactant concentration on the responsiveness of a thermoresponsive copolymer/surfactant mixture with potential application on "Smart" foams formulations. J. Colloid Interface Sci. 2018, 512, 455-465, https://doi.org/10.1016/j.jcis.2017.10.090.

38. Holland, P.M., Rubingh, D.N. Mixed Surfactant Systems. ACS Symposium Series American Chemical Society: Washington, DC 1992, 501, ISBN 9780841224681.

39. Rosen, M.J. Surfactants and interfacial phenomena; Rosen, M.J., Ed.; Wiley Interscience: New York, 1989.

40. Scamehorn, J.F. Phenomena in mixed surfactant systems; ACS Symposium Series: Washington DC, 1986.

41. Cross, J., Singer, E.J., Eds. Cationic Surfactants, Analytical and Biological Evaluation. Crc press: Boca Raton, London, New York;

42. Carnero R, C.; Aguiar, J. Mixed micelles of triton X100: interaction, composition, stability and microenvironmental properties of the aggregates. Mol. Phys. 1999, 97, 1095-1103, https://doi.org/10.1080/00268979909482910.

43. Sharma, K.S.; Patil, S.R.; Rakshit, A.K. Study of the cloud point of C12En non-ionic surfactants: effect of additives. Colloids Surfaces A Physicochem. Eng. Asp. 2003, 219, 67-74, https://doi.org/10.1016/S09277757(03)00012-8.

44. Maeda, H. Electrostatic Contribution to the Stability and the Synergism of Ionic/Nonionic Mixed Micelles in Salt Solutions. J. Phys. Chem. B 2004, 108, 6043-6051, https://doi.org/10.1021/jp037799w.

45. Azum, N.; Naqvi. A.Z.; Rub, M.A.; Asiri, A.M. Multi-technique Approach towards Amphiphilic DrugSurfactant Interaction: A Physicochemical Study. J. Mol. Liq. 2017, 240, 189-195, https://doi.org/10.1016/j.molliq.2017.05.066.

46. Sharma, K.S.; Rodgers, C.; Palepu, R.M.; Rakshit, A.. Studies of mixed surfactant solutions of cationic dimeric (gemini) surfactant with non-ionic surfactant C12E6 in aqueous medium. J. Colloid Interface Sci. 2003, 268, 482-488, https://doi.org/10.1016/j.jcis.2003.07.038.

47. Devínsky, F.; Masárová, L.; Lacko, I. Surface activity and micelle formation of some new bisquaternary ammonium salts. J. Colloid Interface Sci. 1985, 105, 235-239, https://doi.org/10.1016/0021-9797(85)903637.

48. De, S.; Aswal, V.K.; Goyal, P.S.; Bhattacharya, S. Role of Spacer Chain Length in Dimeric Micellar Organization. Small Angle Neutron Scattering and Fluorescence Studies. J. Phys. Chem. 1996, 100, 1166411671, https://doi.org/10.1021/jp9535598.

49. Azum, N.; Rub, M.A.; Asiri, A.M.; Bawazeer, W.A. Micellar and interfacial properties of amphiphilic drug- 
non-ionic surfactants mixed systems: Surface tension, fluorescence and UV-vis studies. Colloids Surfaces A Physicochem. Eng. Asp. 2017, 522, 183-192, https://doi.org/10.1016/j.colsurfa.2017.02.093.

50. Mirgorodskaya, A.B.; Kushnazarova, R.A.; Lukashenko, S.S.; Zakharova, L.Y. Self-assembly of mixed systems based on non-ionic and carbamate-bearing cationic surfactants as a tool for fabrication of biocompatible nanocontainers. J. Mol. Liq. 2019, 292, 111407, https://doi.org/10.1016/j.molliq.2019.111407.

51. Ali, M.S.; Anjum, K.; Khan, J.M.; Khan, R.H.; Kabir-ud-Din Complexation behavior of gelatin with amphiphilic drug imipramine hydrochloride as studied by conductimetry, surface tensiometry and circular dichroism studies. Colloids and Surfaces B: Biointerfaces 2011, 82, 258-262, https://doi.org/10.1016/j.colsurfb.2010.08.043.

52. Ali, M.S.; Rub, M.A.; Khan, F.; Al-Lohedan, H.A.; Kabir-ud-Din Interaction of amphiphilic drug amitriptyline hydrochloride with $\beta$-cyclodextrin as studied by conductometry, surface tensiometry and viscometry. J. Mol. Liq. 2012, 167, 115-118, https://doi.org/10.1016/j.molliq.2012.01.004.

53. Ali, M.S.; Al-Lohedan, H.A. Interaction of biocompatible polymers with amphiphilic phenothiazine drug chlorpromazine hydrochloride. J. Mol. Liq. 2013, https://doi.org/10.1016/j.molliq.2012.10.037.

54. Ali, M.S.; Rub, M.A.; Khan, F.; Al-Lohedan, H.A. Thermodynamic, interfacial and hydrodynamic aspects of interaction of cationic drug amitriptyline hydrochloride with anionic and non-ionic polymers. J. Mol. Liq. 2013, 180, 200-206, https://doi.org/10.1016/j.molliq.2013.01.001.

55. Ali, M.S.; Suhail, M.; Ghosh, G.; Kamil, M.; Kabir-ud-Din Interactions between cationic gemini/conventional surfactants with polyvinylpyrrolidone: Specific conductivity and dynamic light scattering studies. Colloids and Surfaces A: Physicochemical and Engineering Aspects 2009, 350, 51-56, https://doi.org/10.1016/j.colsurfa.2009.08.033.

56. Das, S.; Mondal, S.; Ghosh, S. Physicochemical Studies on the Micellization of Cationic, Anionic, and Nonionic Surfactants in Water-Polar Organic Solvent Mixtures. J. Chem. Eng. Data 2013, 58, 2586-2595, https://doi.org/10.1021/je4004788.

57. Clint, J.H. Micellization of mixed non-ionic surface active agents. J. Chem. Soc. Faraday Trans. 1 Phys. Chem. Condens. Phases 1975, 71, 1327, https://doi.org/10.1039/f19757101327.

58. Holland, P.M.; Rubingh, D.N. Nonideal multicomponent mixed micelle model. J. Phys. Chem. 1983, 87, 1984-1990, https://doi.org/10.1021/j100234a030.

59. Motomura, K.; Yamanaka, M.; Aratono, M. Thermodynamic consideration of the mixed micelle of surfactants. Colloid Polym. Sci. 1984, 262, 948-955, https://doi.org/10.1007/BF01490027.

60. Maeda, H. A Simple Thermodynamic Analysis of the Stability of Ionic/Nonionic Mixed Micelles. J. Colloid Interface Sci. 1995, 172, 98-105, https://doi.org/10.1006/jcis.1995.1230.

61. Rodenas, E.; Valiente, M.; del Sol Villafruela, M. Different Theoretical Approaches for the Study of the Mixed Tetraethylene Glycol Mono- n -dodecyl Ether/Hexadecyltrimethylammonium Bromide Micelles. $J$. Phys. Chem. B 1999, 103, 4549-4554, https://doi.org/10.1021/jp981871m.

62. Lange, H.; Beck, K.-H. Zur Mizellbildung in Mischlösungen homologer und nichthomologer Tenside. Kolloid-Zeitschrift und Zeitschrift für Polym. 1973, 251, 424-431, https://doi.org/10.1007/BF01498689.

63. Ren, Z.H. Interacting behavior between amino sulfonate amphoteric surfactant and octylphenol polyoxyethylene ether (7) in aqueous solution and pH effect. J. Ind. Eng. Chem. 2014, 20, 3649-3657, https://doi.org/10.1016/j.jiec.2013.12.061.

64. Ren, Z.; Hou, Y.; Lu, X. A case of GIS application in agricultural project management. In Proceedings of the 2013 Second International Conference on Agro-Geoinformatics (Agro-Geoinformatics) 2013, 18-21.

65. Barai, M.; Mandal, M.K.; Sultana, H.; Manna, E.; Das, S.; Nag, K.; Ghosh, S.; Patra, A.; Panda, A.K. Theoretical Approaches on the Synergistic Interaction between Double-Headed Anionic Amino Acid-Based Surfactants and Hexadecyltrimethylammonium Bromide. J. Surfactants Deterg. 2020, https://doi.org/10.1002/jsde.12412.

66. Patel, U.; Parekh, P.; Sastry, N.V.; Aswal, V.K.; Bahadur, P. Surface activity, micellization and solubilization of cationic gemini surfactant-conventional surfactants mixed systems. J. Mol. Liq. 2017, 225, 888-896, https://doi.org/10.1016/j.molliq.2016.11.017.

67. Ren, Z.H.; Huang, J.; Zheng, Y.C.; Lai, L.; Yu, X.R.; Chang, Y.L.; Li, J.G.; Zhang, G.H. Mixed micellization of binary mixture of amino sulfonate amphoteric surfactant with octadecyltrimethyl ammonium bromide in water/isopropanol solution: Comparison with that in aqueous solution. J. Dispers. Sci. Technol. 2019, 40, 1353-1359, https://doi.org/10.1080/01932691.2018.1515021. 